\title{
ESCENAS DE CONFESIÓN EN LOS SIETE LOCOS Y LOS LANZALLAMAS DE ROBERTO ARLT: MALESTAR Y ACONTECIMIENTO'
}

\author{
Confession scenes in Roberto Arlt's Los siete locos y Los lanzallamas: \\ Uneasiness and Event
}

\section{ANDREA KOTTOW KEIM}

\section{UNIVERSIDAD ANDRÉS BELLO (CHILE) akottow@yahoo.com}

Doctora en Historia de la Medicina por la Freie Universität Berlin, Licenciada en Lengua y Literatura Hispánicas, y Magíster en Literatura General y Comparada de la Universidad de Chile. Actualmente se desempeña como académica en el Departamento de Humanidades de la Universidad Andrés Bello. Es investigadora en el campo de los estudios culturales y literarios, y se ha especializado en las relaciones entre literatura y medicina con un enfoque biopolítico, concentrándose en las representaciones y significaciones de enfermedad y salud.

\section{RECIBIDO: 22 DE AGOSTO DE 2017}

RESUMEN: El planteamiento inicial del artículo postula que las teorías psicoanalíticas comenzaron a circular y a popularizarse más allá de los marcos médicos y psiquiátricos en América Latina y Argentina, específicamente en Buenos Aires, en las décadas del '20 y '30. Las ideas freudianas producen una profunda transformación en la concepción del sujeto, de la relación que mantiene este consigo mismo y con los otros, emergiendo un sujeto atravesado por el inconsciente. La literatura de este período se puebla de figuras literarias que exploran esta dimensión inconsciente del sujeto. A partir de una lectura de las novelas Los siete locos (1929) y Los lanzallamas (1931) de Roberto Arlt, el texto explora la figura de las escenas de confesión que en ellas se darían, posibilitando los textos literarios la aparición de un dispositivo psicoanalítico, que gira en torno a una verdad de carácter dialógico y escénico.

PALABRAS ClaVE: Roberto Arlt, Psicoanálisis, escenas de confesión, malestar, acontecimiento.

\section{ACEPTADO: 17 DE NOVIEMBRE DE 2017}

ABSTRACT: The article proposes that psychoanalytic theories began to circulate, - and to be popular beyond medical and psychiatric circles -, in LatinAmerica and Argentina, especially in Buenos Aires, in the 1920s and 1930s. The ideas of Freud produce a profound transformation in the concept of the subject, of the relationship he has with itself and with others, letting a subject emerge that is marked by the unconscious. Starting from an interpretation of the novels Los siete locos (1929) and Los lanzallamas (1931) by Roberto Arlt, the article examines the figure of confession scenes. Through these scenes, a psychoanalytic dispositive emerges, involving a dialogical and scenic truth.

KEYWORDS: Roberto Arlt, Psychoanalysis, Confession Scenes, Uneasiness, Event.

\footnotetext{
${ }^{1}$ Este artículo fue elaborado en el marco del Proyecto Jorge Millas Di-15-17 / JM de la Universidad Andrés Bello, titulado "La puesta en escena de lo psicoanalítico en las literaturas chilenas y argentinas de mediados de siglo".
} 
Lo importante, decía el abate Galiani a Madame d’Epinay, no es curarse, sino vivir con sus enfermedades.

A. CAMUS

\section{PlanTEAMIENTOS INTRODUCTORIOS:}

En 1910 se celebra en Buenos Aires el Congreso Internacional Americano de Medicina e Higiene. En este encuentro, un médico chileno de origen alemán -Germán Greve Schlegel- presenta un trabajo titulado "Sobre psicología y psicoterapia de ciertos estados angustiosos", en el cual articula sus experiencias clínicas con ciertos enfoques provenientes del psicoanálisis freudiano. Con su intervención, Greve Schlegel se convertirá en uno de los primeros latinoamericanos en hacer referencia a Sigmund Freud. Tanto para el contexto argentino, como para el chileno, esta especie de hito fundacional, más allá de su valor anecdótico, permite rastrear las primeras recepciones que del psicoanálisis y las teorías freudianas se hicieran en estas latitudes ${ }^{2}$.

Para el caso argentino, el psicoanálisis aparece, en sus inicios, amalgamado (Plotkin, 2003: 28) con otras teorías que se manejaban en los círculos psiquiátricos de las primeras décadas del siglo $\mathrm{XX}$, como, por ejemplo, la teoría de la degeneración elaborada por el psiquiatra francés Benedict August Morel. Los planteamientos de este último estaban dirigidos a llenar un vacío explicativo que se presentaba con relación a la herencia de ciertas enfermedades: probado el carácter hereditario de una serie de patologías físicas por las recientes teorías de la herencia, surgía la pregunta por la aparición de enfermedades psiquiátricas en grupos familiares que parecían perfectamente sanas. Morel reconocía, entonces, que ciertas anomalías de gravedad menor estaban destinadas a aumentar, en su traspaso, de una generación a otra. Un simple desvío que podía escaparse al diagnóstico, en la siguiente generación se convertiría en un mal psiquiátrico mayor. Además de la teoría de la degeneración, pero en su cercanía, estaban en boga las ideas criminalistas del italiano Cesare Lombroso, que sostenían la tesis de un perfil fisiológico del criminal. A su vez, Lombroso indagaba en las relaciones entre locura y genialidad. La importancia de vincular la teoría psicoanalítica con estas otras aproximaciones al complejo mundo de la psique, reside en que se pone de manifiesto su temprano potencial de exceder el marco del saber médico y convertirse en una teoría de corte cultural. Tanto las tesis de Morel como los planteamientos de Lombroso gozaron en sus lugares de proveniencia de una amplia recepción en círculos no médicos, convirtiéndose en verdaderas cifras para comprender la decadencia de la Europa finisecular. El ánimo general del así llamado fin de siècle encontró en estas teorías médicas un modelo para pensar y expresar el malestar y la sensación de

\footnotetext{
2 Así lo establecen para el caso argentino Hugo Vezzetti en Freud en Buenos Aires, Mariano Plotkin en su Freud en las pampas y Mariano Ruperthuz en Freud en Chile, señalándose la referencia de Greve -cuya cita al médico vienés fue, a su vez, atestiguada por el mismo Freud- como evidencia para postular que a partir de 1910, Freud y el psicoanálisis comienzan a formar parte de las teorías médicas consideradas en la psiquiatría. No obstante, tanto Vezzetti como Plotkin sostienen que la entrada del psicoanálisis al mundo médico bonaerense fue lento y estuvo marcado por una gran desconfianza, por orientarse la psiquiatría argentina en Francia y por dudarse de la cientificidad de las teorías freudianas. Véase Hugo Vezzetti, Freud en Buenos Aires (1996), Mariano Ben Plotkin, Freud en las pampas (2003) y Mariano Ruperthuz, Freud en Chile (2015).
} 
declive que embargaba al mundo letrado. Es sintomático, en este sentido, que el psicoanálisis incluso en los círculos científicos se vinculaba con determinados conjuntos de ideas que compartían algunos rasgos que hacían proclive su rebase a otros ámbitos del quehacer intelectual. De este modo, se vuelve casi imposible distinguir entre una recepción estrictamente médica y otra cultural del psicoanálisis en Argentina (Plotkin, 2003: 28). Tal como postula Hugo Vezzetti, se revela muy precozmente en la recepción freudiana en Argentina "una matriz de lectura, propiamente cultural” (Vezzetti, 1996: $15)$.

Convoco, entonces, a entender el psicoanálisis desde una perspectiva amplia, considerándose "la combinación de los modos particulares de difusión y recepción de diversas culturas y sociedades" (Plotkin, 2003: 18) de las ideas psicoanalíticas. Comprender el psicoanálisis en tanto artefacto cultural permite ir más allá de los autores, espacios y prácticas discursivas en los que determinadas teorías llegan a encarnarse, para abrirse a la "historia de la implantación, la apropiación y la reelaboración [de las ideas] en culturas diferentes" (Plotkin, 2003: 18). Mariano Ruperthuz propone no referirse al psicoanálisis en singular sino pluralizar el término, insistiendo en que se trata de:

Un sistema de saberes y de creencias [...] que [...] ha tenido la capacidad de constituir una 'subcultura' en diversos lugares del mundo, es decir desbordar ampliamente el ámbito inicial de utilización difundiéndose por canales diversos tanto dentro de la cultura letrada y científica como de la cultura popular (Ruperthuz, 2015: 27).

En su estudio sobre la genealogía de las ideas psicoanalíticas en la Argentina, Mariano Plotkin identifica la década del 20’ como el período en que el psicoanálisis abandona su restricción al ámbito médico -que por lo demás en un primer momento se mostró en gran medida desconfiado frente a ideas consideradas extranjeras, excesivamente focalizadas en la sexualidad y dudosas en su rigor científico- para gozar de popularidad y convertirse en un objeto de consumo cultural. El mismo Plotkin relaciona la paulatina apertura hacia el psicoanálisis con un creciente interés por parte de la intelectualidad latinoamericana en corrientes filosóficas de origen europeo continental, alejadas del positivismo.

Este panorama dibujado es importante para plantear que el campo cultural de la primera mitad del siglo XX en Argentina se encuentra fuertemente marcado por aspectos centrales de las teorías psicoanalíticas freudianas, donde se vinculan y se articulan con discursos sobre la modernidad, la urbanización, la salud e higiene pública, la nación y la raza, la sexualidad y el deseo. Expresado en las palabras de Vezzetti, "Freud viene asociado menos al campo de problemas de la psiquiatría que como protagonista de un movimiento intelectual con vastas repercusiones en la cultura de su tiempo" (Vezzetti, 1996: 22). La literatura es uno de los campos en los que se manifiesta esta permeabilidad de las ideas psicoanalíticas, si bien en muchos casos no se trata, desde el campo literario, de una recepción ni rigurosa ni fidedigna, sino forma más bien parte de lo que el mismo Vezzetti llama una de "sus expresiones "silvestres" (Vezzetti, 1996: 18). Una serie de autores de este período puede ser leída bajo este prisma, haciéndose manifiestas las transformaciones en las visiones sobre el sujeto, la relación que mantiene consigo mismo y con otros, las definiciones e ideas 
acerca de la salud y la enfermedad, la sexualidad, el deseo y su vínculo con la cultura. Si comprendemos el psicoanálisis como un conjunto heterogéneo de ideas que producen una profunda mutación de las coordenadas del campo cultural en la primera mitad del siglo XX, esto es, sin lugar a dudas, porque se evidencia en las formas representacionales que emergen del sujeto en la producción literaria. Más allá de probar o no que los autores escriben bajo el alero de sus lecturas efectivas de Sigmund Freud u otras teorías psicoanalíticas, la propuesta que quisiera hacer aquí apunta a atender al impacto que tienen las ideas psicoanalíticas, y a los cambios que producen en las visiones sobre el sujeto y su relación con la cultura. Ni el lenguaje, ni la sexualidad, ni la razón serán los mismos tras la irrupción de las teorías freudianas en el campo intelectual, aunque estas hayan sido leídas en formas indirectas, muchas veces a través de traducciones o comentarios de otros, o incluso solo recibidas de oídas y por sus manifestaciones marginales.

Entre otros, y esta es la lectura que a continuación intento desplegar, las obras Los siete locos y Los lanzallamas de Roberto Arlt se encontrarían colmadas de estas miradas transformadas sobre el sujeto, puestas en circulación por el psicoanálisis entendido en el sentido amplio explayado más arriba. En ambas novelas de Arlt se pondría en juego un sujeto reñido consigo mismo y con los demás, a partir de la incompatibilidad de sus deseos con lo que la vida comunitaria pareciera exigir de él. De este modo, emergería en estas obras un sujeto que puede ser analizado bajo la noción del malestar freudiano, que postula la producción de una necesaria negatividad en el sujeto por su convivencia en sociedad. A partir de la represión constante de sus pulsiones, el sujeto acumula un malestar que marca el vínculo de él consigo mismo y con los otros. Simultáneamente se iría difuminando en las obras de Arlt la idea de lo que es considerado normal y anormal, sano y enfermo. Para el proyecto moderno, y así lo han planteado las discusiones biopolíticas impulsadas por Foucault, y seguidas, entre otros, por Esposito y Agamben, un ideal tanto individual como colectivo de salud es fundamental para vehicular la producción y la reproducción anhelada y requerida por la modernidad. Con un sujeto en el cual potencialmente el inconsciente contradice lo que su consciente le dicta, en el que su deseo puede adquirir matices (auto)destructivos, y donde la relación con los demás está marcada por una imposibilidad de comprensión elemental, este modelo de salud entra en graves problemas. Para el psicoanálisis y la visión del sujeto que de él se desprende, el sujeto no está nunca del todo sano. Y la relación que el sujeto establece con los demás al convivir en comunidad implica aspectos enfermizos.

Este sujeto aparece en las novelas de Arlt en tanto efecto de una serie de actos de habla que analizaré bajo la figura de la confesión; las dos novelas son la urdimbre de un oyente que ha sido depositario de las confesiones de su protagonista, Remo Erdosain. Las novelas están constituidas por varias y variadas conversaciones que mantienen sus personajes -muchas de ellas adoptan un tono confesional-, todas recogidas y reproducidas por Erdosain a su confesor, quien pone a disposición del lector el texto. No se trata, no obstante, de una mera reproducción, sino, y así la propuesta de lectura, el oyente adoptaría una posición que recuerda a la escucha psicoanalítica; interpreta, selecciona y busca lo importante no siempre en lo que pareciera serlo, atento a lo latente. De esta forma, será el 
lenguaje el que se encuentra en el centro de las novelas, siendo las figuras literarias -esbozos de sujetos- meros efectos de los discursos puestos en circulación.

\section{ESCENAS DE CONFESIÓN EN LOS SIETE LOCOS}

En 1929 Roberto Arlt publica sus Siete locos, novela extraordinaria en muchos sentidos. Se trata de un texto complejo, donde al mismo tiempo pareciera pasar de todo y nada. Simultáneamente colmada de múltiples sucesos, la novela ostenta el insoportable vacío de que, finalmente, nunca ocurrirá nada. La obra está forjada en torno a conversaciones varias que van sucediéndose continuamente, reduciendo la trama al mínimo y dando al lenguaje puesto en escena el verdadero protagonismo. Una de las particularidades en las que quisiera insistir en este trabajo es que la escena que configura la novela lleva el signo de lo psicoanalítico. Toda la novela se articula a partir de una confesión: la de Augusto Remo Erdosain a su confesor, quien entrega al público lector su escrito, constituido desde lo que Erdosain le ha contado. No es sino algo avanzada la obra, que el lector, a través de pequeñas huellas textuales que se vuelven más y más explícitas en el transcurso del texto, reconstruye que la novela es posibilitada por la confesión. Tras varias páginas, podemos leer:

El cronista de esta historia no se atreve a definirlo a Erdosain, tan numerosas fueron las desdichas de su vida, que los desastres que más tarde provocó en compañía del Astrólogo pueden explicarse por los procesos psíquicos sufridos durante su matrimonio.

Aún hoy, cuando releo las confesiones de Erdosain, paréceme inverosímil haber asistido a tan siniestro desenvolvimiento de impudor y de angustia.

Me acuerdo. Durante aquellos tres días en que estuvo refugiado en mi casa, lo confesó todo (Arlt, 2007: 80).

De esta forma, quien da cuenta de la historia es un receptor, interventor e intérprete de una confesión recibida. La situación de confesión, que quisiera proponer como escena psicoanalítica, se constituye en tanto fundamental para la estructura de la novela. En la confesión participan al menos dos agentes: quien se confiesa y el confesor, a quien le es atribuido el poder de su posición por quien se confiesa, adoptando ambos los lugares de analizado y analista respectivamente. La confesión posibilita la aparición de una verdad antes ocultada y reprimida. Se trata de una verdad que no opera en términos de su verificabilidad, sino desde su fuerza impositiva, atravesando al sujeto y marcando la relación de este consigo mismo y con el mundo circundante. La escena además presupone una concepción del lenguaje que cuestiona y complica su capacidad comunicativa. No aparece como herramienta al servicio de una razón ordenadora del mundo, sino más bien en tanto fuente constante de equívocos y contradicciones que, a su vez, son los medios esquivos a través de los cuales se visibiliza esta "verdad” psicoanalítica.

En una conversación entre el Astrólogo y Erdosain, este le replica al gran estratega frente a la pregunta por qué ha actuado de ciertos modos en su vida: 
Eso es lo que yo no sé. [...] Aparentemente somos todo eso, pero en el fondo, adentro, más debajo de nuestra conciencia y de nuestros pensamientos hay otra vida más poderosa y enorme [...] es decir, la verdad de nosotros mismos (Arlt, 2007: 67).

Esa verdad, a la que el sujeto no tiene acceso de formas directas, solo centellea, de modo fragmentado y oblicuo, entre las palabras que intercambian los personajes: en las contradicciones y tensiones, en los lapsus y en los sueños, en los síntomas físicos que acompañan la mera denotación de lo dicho.

La situación dialógica implica que solo la interacción entre esas dos instancias -la del habla y la de la escucha- son capaces de hacer emerger una verdad que antes de esa escena de confesión estaba ocultada. Solo el fluir del habla que es impulsado por otro que interviene, y que es, en definitiva, quien recompone el relato, termina por poner en juego la escena. Al modo de los relatos clínicos de Freud, hay alguien que lee, descifra, selecciona, jerarquiza, otorga o resta importancia. En algunos pasajes, el narrador de Los siete locos interviene con notas a pie de página; en otros cree necesario describir las posiciones, actitudes y gestos físicos que acompañan la confesión de Erdosain, y en otros aporta con interpretaciones, como cuando acota:

En el curso de esta historia he olvidado decir que cuando Erdosain se entusiasmaba, giraba en torno de la 'idea' eje con palabras numerosas. Necesitaba agotar todas las posibilidades de expresión, poseído por ese frenesí lento que a través de las frases le daba a él la conciencia de ser un hombre extraordinario y no un desdichado (Arlt, 2007: 59-60).

Emulando la posición de un analista, quien recibe el relato de Erdosain aporta con una exégesis de lo escuchado, donde el lenguaje es la materia prima a ser interpretada. Así, tal como en el psicoanálisis, la importancia de lo ocurrido es desplazada por las formas en que el sujeto da cuenta de los sucesos, y estos últimos no pasan a ser sino efectos de un discurso. A su vez, quien escucha no reproduce fidedignamente el contenido de lo dicho por Erdosain, como si de una mera transcripción se tratase, sino incluye una lectura de lo sintomático de quien habla: el cómo se dice algo significa más allá del qué se dice. Las formas se superponen a los supuestos fondos, las superficies se vuelven profundidades.

La teórica norteamericana Linda Ruth Williams destaca en su estudio acerca de las vinculaciones entre el psicoanálisis y el sujeto literario, que uno de los principios básicos del psicoanálisis es que el inconsciente se revela a través de los modos del decir, de lo que llama "estilo" (Williams, 1995: 5). Es en este punto que Williams reconoce un poderoso vínculo entre la práctica psicoanalítica y la literaria, en el sentido de una correspondencia, que podríamos llamar hermenéutica, entre, de un lado, quien habla y quien escucha en el análisis, y escritor y lector en la práctica literaria, del otro. Postula Williams:

The patient [...] does not offer up to the analyst an open "text" thick with overt significance, but rather a linguistic and symbolic puzzle or jumble, which requires the training of peculiarly "literary" eye to read it powerfully (Williams, 1995: 7). 
La lectura de signos forma parte constitutiva del quehacer del psicoanálisis y de la literatura, y su "verdad" resulta de estos procesos de desciframiento. Es más, no existe ninguna verdad que pueda comprobarse de un modo que se encuentre fuera y opere autónomamente de estos continuos procesos de producción y recepción, de escritura y lectura, de habla y escucha. Esto trae consigo una necesaria revisión de los términos de la verdad y la ficción/mentira, por un lado, y de lo real e irreal, por el otro. Para el estatuto del inconsciente en el psicoanálisis, en palabras de Williams, esto implica que " $[u]$ nconscious fantasy is neither real nor unreal, except that it has a paramount reality in the life and construction of the subject" (Williams, 1995: 17).

Lo llamativo en la obra de Arlt es que, al modo de las muñecas rusas, las confesiones van conteniendo otras situaciones de confesiones. Es decir, hay una especie de puesta en abismo del dispositivo del decir y escuchar. El confesor escucha y "lee" a Erdosain, pero a su vez los diversos personajes que pueblan Los siete locos se convierten en quienes hablan y escuchan a otros, adoptando distintas posiciones dentro de estos modelos de productores y receptores de “verdades”3. Están, por ejemplo, las confesiones que hace Barsut a Erdosain. El texto subraya incluso el vínculo que el gesto excesivo de la figura de la confesión establece entre ambos personajes:

Y muchas veces imaginaba que Barsut lo recordaba a través de los días con el odio que se le toma a las personas a quienes se han hecho demasiadas confidencias. Pero no se podía dominar, porque apenas llegaba a la casa de Erdosain, volcaba en las orejas de éste cubos de desdichas, aunque sabía que Erdosain se regocijaba con ellas” (Arlt, 2007: 21).

El confesor -en este caso Erdosain-, de este modo, no solo se vuelve el depositario de las verdades de quien confiesa -Barsut-, sino también del odio que este último proyecta sobre él por conocer aquello que solo la confesión ha hecho emerger. Un día Barust llega a golpear brutalmente a Erdosain; tras dejarlo inconsciente y sangrando, el agresor ayuda a su víctima a volver a incorporarse y a lavarse, explicando su exabrupto a partir de "un impulso". Lo que requiere Barsut es continuar su confesión: "Es necesario que te cuente todo. ¿A quién sino a vos le podría contar todas estas cosas que hacen doler el corazón?” (Arlt, 2007: 56). Parte de este mismo capítulo es el momento en que Erdosain concibe la idea de matar a Barsut, de lo que el lector se entera por el confesor último que recibe el relato de Erdosain. Me parece decidora la manera en que el texto va articulando, en términos de su estructura narrativa, este punto climático de la novela:

Barsut ni remotamente se imaginó que en aquel instante, Remo acababa de condenarlo a muerte. Explicándome luego las circunstancias de esa concepción, Erdosain me decía [...] Yo, en aquel instante, supe que tenía que hacerlo matar a Barsut, y él, frente a mí, amontonando palabras inútiles no se imaginaba que yo, con la boca hinchada, la nariz dolorida, retenía una alegría estupenda, un deslumbramiento semejante al que se experimenta cuando lo que se ha descubierto es fatal como una ley matemática. Quizás existe

\footnotetext{
${ }^{3}$ Las posiciones de quien se confiesa y quien opera de confesor no son estáticas en la obra de Arlt. Es decir, los diversos personajes van adoptando tanto el lugar de quien habla como de quien escucha, de alguien que se confiesa como de quien recibe la confesión. No están, de este modo, marcadas por una supuesta superioridad de uno sobre el otro, sino tan solo se evidencian como posiciones que se ocupan dentro de un entramado dialógico.
} 
también una matemática del espíritu cuyas terribles leyes no son tan inviolables como las que rigen las combinaciones de los números y de las líneas (Arlt, 2007: 59).

En este recuerdo de Erdosain, que remite al momento de su concepción de asesinar a Barsut, el narrador de la novela incorpora una nota a pie de página que acota:

Nota del comentador: Este capítulo de las confesiones de Erdosain me hizo pensar más tarde si la idea del crimen a cometer no existiría en él en una forma subconsciente, lo que explicaría su pasividad frente a la agresión de Barsut (Arlt, 2007: 59).

La novela revela en este episodio su forma de estar concebida: a saber, a manera de escenas de confesiones continuas, que hacen aparecer verdades oblicuas, cuya emergencia a la superficie del relato solo se posibilita por las situaciones de habla y escucha. No hay prácticamente relato objetivado en la novela: esta está fraguada a partir de múltiples situaciones dialógicas, de las cuales la que pone en juego toda la narración es la confesión de Erdosain al autodenominado comentador. Cabe subrayar que este confesor se titula comentador, señalándolo desde el mismo nombre como intérprete y no mero reproductor o testigo objetivo. Esta confesión "macro", a su vez da pie a varias otras situaciones confesionales, como la recién señalada escena de Barsut con Erdosain. Existe, por lo demás, una diferencia importante entre Erdosain, por un lado, y el Astrólogo y sus pares -el Buscador de oro y El mayor-, por el otro. Mientras que el proyecto del Astrólogo está enmarcado en la instauración de un nueva Sociedad, para la cual se requiere pensar una estructura económica, una forma de jerarquización de los poderes así como los valores que la sustentan -todos pasados por una recepción salvaje de Marx, Nietzsche y Freud-, los motivos de Erdosain son mucho más enrevesados y se resisten, una y otra vez, a ser subordinados a un sistema racional de explicación. Uno se podría preguntar, ¿por qué se conversa tanto en la novela de Arlt? Me parece que habría que intentar una respuesta no a partir de la confianza en el lenguaje como medio de comunicación eficaz, sino precisamente a partir de su constante fracaso. El lenguaje es el encubrimiento con el cual todos los personajes se envuelven. Están inmersos en él y no pueden deshacerse de él. Las conversaciones, muchas veces virulentas, parecen evidenciar la desesperación de esa condena al lenguaje, en un desolado gesto de desprendimiento, como si se pudiese atravesar la palabra ${ }^{4}$. Piglia ha destacado, en una entrevista recogida en Crítica y ficción, que el relato de Erdosain sería el "del intento de pasar al otro lado, zafarse de la opacidad turbia de la vida cotidiana" (Piglia, 2001: 24), es decir, una especie de paso al acto, una tentativa de salir de la insoportable condena al lenguaje que no hace sino patente que nunca sucede absolutamente nada.

\footnotetext{
4 Daniar Chávez Jiménez niega el estatuto de “conversación” a los diversos actos de habla puestos en juego por los personajes tanto en Los siete locos como en Los lanzallamas: "En el extenso diálogo arltiano no existe el conversar, el discutir, por lo menos no en la forma como el pensamiento griego heredó al pensamiento contemporáneo. La conversación arltiana no formula preguntas, emite o irradia exabruptos; asimismo nunca manifiesta u ostenta respuestas, porque en ningún momento parece buscarlas. Es un constante fluir en una perorata al vacío, en un diálogo/monólogo entre sordos o, mejor aún, en un diálogo/monólogo entre locos, como bien lo expresa el título a la primera de las obras que constituyen el díptico; este diálogo furioso, bestial, continúa distorsionándose con una progresión sorprendente durante la segunda parte, que bien pudo haber sido titulada Los monstruos, como inicialmente tenía estimado Arlt" (Chávez Jiménez, 2010: s/p).
} 


\section{EL ACONTECIMIENTO DEL NO ACONTECER EN LOS LANZALLAMAS}

Dos años tras la publicación de Los siete locos, en 1931 aparece Los lanzallamas, continuación de la historia de Erdosain, el Astrólogo y sus secuaces. Curiosa situación inicial es la que da pie a esta segunda novela: el supuesto asesinato de Barsut que, no obstante, nunca haya efectivamente ocurrido, tortura a Erdosain, impulsándolo finalmente a convertirse en asesino y suicida. Es aquí donde se hace patente una de las observaciones de Ricardo Piglia sobre Roberto Arlt, y que dice relación con el poder de las ficciones. Frente a la pregunta de qué es lo que sería la ficción para Arlt, Piglia responde:

Sobre todo la posibilidad de hacer creer. [...] en Arlt, la ficción se transforma y se metamorfosea y a menudo se identifica con la estafa, con el fraude, con la falsificación, con la delación. Formas todas donde los relatos actúan, tienen poder, producen efectos" (Piglia, 2001:24).

El poder performático del relato del asesinato de Barsut transforma a Erdosain en un paria social que termina viviendo su posición de forma cada vez más radical, lo que también podría denominarse locura. Si nos atenemos a Piglia, la comprensión de la locura en Arlt pasaría por una "ruptura de lo posible. Estar loco, en Arlt, es cruzar el límite, es escapar del infierno de la vida cotidiana. O mejor, habría que decir, la locura es la ilusión de salir de la miseria” (Piglia, 2001: 26) ${ }^{5}$.

La novela Los Lanzallamas se sostendría, así nuestra propuesta, sobre el constante suceder de un no-acontecimiento. La trama estaría articulada en torno a sucesos ya acontecidos, por suceder o presentes en tanto proyecciones imaginarias. El texto, de este modo, se desplegaría a partir de que el acontecimiento -entendido como un golpe de lo real que obliga a reordenar la visión de mundo y las narraciones en que esta emerge- consiste en que este siempre ya ha sucedido o está por suceder. Así, el sujeto viviría continuamente desplazado de la experiencia de aquello que verdaderamente marca su vida y se vería incapacitado de descifrar las claves de lo que rige su existencia. Las conversaciones y confesiones que articulan la trama se vuelven el espacio en que este no-acontecimiento y la desesperación por no poder asirlo se abren paso.

\footnotetext{
${ }^{5}$ A esta mirada sobre la locura en Arlt, postulada por Piglia, quisiera agregarle la visión que despliega Josefina Ludmer en El cuerpo del delito sobre Los siete locos y Los lanzallamas, y que me parece relevante para mi propuesta de pensar el dispositivo psicoanalítico en el díptico arltiano. Ludmer lee una serie de locos y locuras en la literatura argentina en tanto cifra de un derrumbe del Estado liberal: "[...] la locura en la literatura argentina cuenta la historia de ciertos procesos políticos que acompañan el camino de la modernización hacia la democracia en ese ciclo (y después cuenta el camino hacia el primer golpe de estado, en 1929, con Los siete locos). Y lo cuenta porque en 'los locos' (en las series de cuentos de locos) se van representando todas las instituciones, porque la locura es definida en este ciclo como el revés o la negación de las instituciones del estado liberal, tanto en 1889 con Irresponsable de Antonio Podestá, como en la crisis del noventa con el loco de La Bolsa de Julián Martel, como en 'Locos de verano' de Gregorio Laferrèrre en 1905, como en la Locópolis de Soiza Reilly en 1914, como en Los siete locos en 1929” (Ludmer, 2011: 143) Me interesa esta cita, pues refuerza la idea que atraviesa este artículo, a saber, que las concepciones del sujeto que emergen en las primeras décadas del siglo XX en la literatura latinoamericana y que están marcadas por las teorías psicoanalíticas rompen con una tradición anclada en el siglo XIX, en la que las relaciones entre sujeto y comunidad son comprendidas sobre todo desde la continuidad y la posibilidad de armonía. Las nuevas subjetividades, como las que encarnan Erdosain y otras figuras de Arlt, implican de este modo también un cuestionamiento de las concepciones ilustradas que imaginaban a una ciudadanía racional en tanto base para un proceso modernizador exitoso.
} 
Ilai Rowner, en su estudio sobre el evento literario, lo define a partir de un momento de crisis, que simultáneamente se articula como una puesta en suspensión de cualquier conjunto de valores de verdad, una crisis de la representación y del mismo lenguaje, involucrando al mismo tiempo al productor del trabajo como a su receptor. Más allá de pensar en las figuras reales de autor y lector, se tendría que reflexionar, a su vez, en todas las instancias narrativas implicadas en una novela como Los lanzallamas, que como ya se ha destacado para el caso de Los siete locos, es un texto construido a partir de contantes puestas en juego del habla y de la escucha en tanto momentos liminales y de crisis. Para Rowner, en la literatura se recalcaría el particular momento del exceso o la falta de sentido, donde deja de existir una experiencia asentada y cierta del mundo, ni tampoco prevalecen reglas claras para la creación. Es por ello, que la literatura es el espacio donde el acontecimiento se muestra en una paradojal situación, en la que se entretejen el no suceso y el suceso, y frente a los cuales la escritura literaria emerge en tanto el hacer mismo del evento:

A reverberating gong, an unaccountable something, an frightened unhappening, a state of suspense and affliction - each of these enigmatic experiences of the event requires an interrogation that transcends the close realms of history of literature, generic classification, or traditional poetics, and yet [...] the event`s dazzling reality and compelled amazement may constitute the energetic vitality of all stylistically great fictional works (Rowner, 2016: 26-27).

En el caso de Arlt, bien sabido es el posicionamiento extraño que se le ha atribuido en el canon de la literatura argentina. Piglia lo llama "un clásico sin legitimidad" (Piglia, 2001: 22), lugar que también está marcado por su particular estilo, que se escabulle a la "buena escritura”, a la corrección literaria. Este estilo -explosivo, bastardo, excesivo- me parece, entra en estrecho vínculo con esta idea del acontecimiento literario, planteada por Rowner. La obra se vuelve este incómodo espacio en el que el lector se enfrenta al traqueteo constante de un no-suceder. Para Rowner, el evento literario no puede ser reducido meramente a una ocurrencia extralingüística o a un incidente textualnarrativo, tampoco a la mimesis de la historia o a la poiesis de la trama. Es más bien una aventura hacia el no-suceso del suceder, hacia el no-lugar del lugar, un avance hacia un factor desconocido responsable por la irregularidad del suceder, y cuya respuesta requiere y demanda una creación lingüística singular.

En Los lanzallamas, esta aventura del no-acontecer se relaciona muy estrechamente con lo planteado más arriba en el análisis propuesto para Los siete locos. Es decir, el suceder de la trama está desplazado hacia las conversaciones que, a su vez, se convierten en exploraciones del atribulado mundo interior de los personajes. Sobre las desventuras de Erdosain, nos comenta el texto:

Vive simultáneamente dos existencias: una espectral, que se ha detenido a mirar con tristeza a un hombre aplastado por la desgracia, y después otra, la de sí mismo, en la que se siente explorador subterráneo, una especie de buzo, que con las manos extendidas va palpando temblorosamente la horrible profundidad en la que se encuentra sumergido (Arlt, 2008: 27). 
Oscar Masotta, en su inaugural texto sobre Roberto Arlt, enfrenta la pregunta acerca de una lectura política de las obras de Arlt, interrogante que, entre otros, ha retomado Sylvia Saítta. Coinciden Masotta y Saítta en la dificultad de vehicular una lectura política tradicional de Arlt, en el sentido de ver en su obra un despliegue de la lucha de clases o un llamado a una revolución proletaria que siga los postulados marxistas. Saítta, en una entrevista que se le hiciera acerca de la obra de Arlt, y refiriéndose específicamente a Los siete locos y Los lanzallamas, sostiene que no habría lucha de clases en estas novelas, "[...] porque leer a Arlt desde un aparato ideológico es muy difícil. En los personajes de Arlt no hay 'conciencia de clase', casi no hay proletariado, hay lúmpenes” (Saítta, 2005: s/p). Más adelante y retomando a su vez ciertas propuestas de David Viñas acerca de la valoración positiva que se hiciera en Los lanzallamas de los anarquistas, agrega: "No quiero decir con esto que Arlt sea anarquista, sino que en su literatura la salida es siempre violenta" (Saítta, 2005: s/ p). Esta violencia, que no se articula en un proyecto, que no está destinada a un cambio social organizado y que se expresa en términos (auto)destructivos, es la que se instala en tanto no acontecimiento, una especie de imposibilidad de manifestación de lo real.

Slavoj Žižek, en uno de sus últimos ensayos, titulado Acontecimiento, plantea que el acontecimiento simbólico se situaría en tanto hecho que al ocurrir "reestructura el campo entero" (Žižek, 2016: 123) y reflexiona:

Ésta es, quizá, la definición más sucinta de lo que es un auténtico acto: en nuestra actividad cotidiana, efectivamente, sólo seguimos las coordenadas (virtual-fantasmáticas) de nuestra identidad, mientras que un acto estricto es la paradoja de un movimiento real que (retroactivamente) cambia las mismas coordenadas virtuales "trascendentales" del ser de su agente -o, en términos freudianos, que no sólo cambia la realidad de nuestro mundo, sino que también "mueve los infiernos" (Žižek, 2016: 126).

En este sentido, el acontecimiento tiene un efecto retroactivo radical, pues transforma el panorama de los hechos de manera irremediable, imposibilitando imaginar un antes intocado por el acontecimiento. El acontecimiento se vuelve necesario; se impone con su fuerza de tal forma que lo que le antecede se difumina.

Volviendo a la idea de Los lanzallamas entendido como la tragedia del no-acontecimiento, lo que quisiera acentuar en esta perspectiva es que el anhelo de Erdosain es que suceda "algo" que tenga tal fuerza impositiva que cambie radicalmente el curso de las cosas. No en un sentido articulado, no como proyecto político, sino más bien entendido desde el escenario desesperado del sujeto atrapado en las trampas de un orden simbólico del que nunca puede escapar. Los intentos, siempre violentos, de Erdosain de producir una transformación -cuya culminación es el crimen, primero imaginado, luego cometido- atentan contra el orden, cualquiera que esta sea, para que todo parta desde cero. 
Me interesa reflexionar en relación a estas aproximaciones a Roberto Arlt -que buscan acentuar las vinculaciones entre las ideas psicoanalíticas y el campo literario, y una concepción donde la visión predominante sobre la cultura se conjuga con el malestar- sobre el rendimiento teórico de la noción de la "escena": la escena de confesión; la escena psicoanalítica. Para ello, retomo las palabras del filósofo chileno Patricio Marchant, uno de los pioneros en articular su proyecto filosófico en clave psicoanalítica: "la verdad de una escena, es decir, al mismo tiempo, clausura de la noción de una verdad trascendental” (Marchant, 2012: 66). Marchant pone el acento en la tradición metafísica de la filosofía, comprometida con la búsqueda de aspectos invariables del sujeto y su relación con el mundo, como el "ser", la "verdad", "la trascendencia”, mirada que expulsaría de sus posibilidades de representación aspectos ligados a la particularidad, la contingencia, la unicidad. La escena precisamente sería la que vehiculiza su visibilización, haciendo evidente la "propiedad" o lo que Marchant llama, orientándose en las teorías psicoanalíticas, el "nombre propio”. Una escena emerge a partir de la suma particular de una serie de elementos: al cambiar la combinatoria, la escena se transforma. Observar una escena implica hacerse cargo de sus particularidades y propiedades, atendiendo a sus detalles. Mirar una escena es abrirse a sus pormenores y ser capaz de invertir las jerarquías entre los elementos que la componen. En este sentido, la operación psicoanalítica puede ser comprendida desde la "escena", dado que busca lo fundamental en aquello que se pretende superfluo, casual o fútil. Aquello que se pensaba un detalle dispensable, puede ofrecerse en tanto clave de desciframiento. Cecilia Sánchez, otra filósofa chilena que se ha movido entre los cruces disciplinares, acentúa la importancia de lo teatral en lo escénico: "lo escénico configura sus propio topos sobre la base de un cruzamiento de relaciones, fuerzas y necesidades cuyo efecto es patético" (Sánchez, 2005: 14). El pathos referido, elemento central del teatro, produce la afectación del observador, su implicancia física que no se deja subyugar a las comprensiones de un yo consciente:

La escena es análoga a un tejido o velo enmarañado que se da a leer de modo condensado y fantasmal. El discurrir de la escena no se refiere a contenidos quiditativos expresados por un yo consciente. Por el contrario, hay códigos que la invaden y la obligan a escindirse, en ese instante se presenta especularizada, habitada por cuerpos y rostros espectrales (Sánchez, 2005: 13).

Cecilia Sánchez está interesada en pensar la escena escritural -la escritura como escena- que debe, entonces, abrirse a "intercepciones". Se trataría de un ejercicio escritural que abandona la linealidad, causalidad, secuencialidad, renunciando al permanente dominio de la razón en las prácticas de lectura y escritura. El gesto de la escena invita a la desmesura, al derroche, a algo que no se encuentra canalizado previamente y que, por lo tanto, no es calculable: esto es lo que tendrían en común escena psicoanalítica y escena teatral, y es lo que en las obras de Arlt analizadas es emulado literariamente. En la escena aparece una "verdad" que no puede ser explicada a partir de la verificabilidad o el cálculo. Sánchez propone: 
La escena teatral es, así, un lugar que hace posible -para quien se encuentre en ella- un modo de aparición escénica. Aquella aparición supone una mirada dispuesta o en disposición de mirar (Sánchez, 20015: 17-18).

La emergencia de esa verdad aparecida en la escena es dependiente de la mirada, en el teatro, y de la escucha, en el psicoanálisis, pero, a su vez, en ambos escenarios se advierte una contingencia particular. Es por ello, que Marchant le niega a la gran tradición filosófica la capacidad de comprender y representar la escena. La "verdad" que se vuelve visible en la escena no tiene carácter universal; es, apenas, una realidad que se devela con tal fuerza que se impone a partir de la imposibilidad de obviarla. Marchant insiste en la posición privilegiada que puede ocupar la literatura en hacer emerger este tipo de verdad ligada al sujeto. Esa verdad, atravesada por la violencia de lo real, no puede ser percibida en forma directa, ni tampoco puede ser reproducida descriptivamente:

El suplemento de artificios de la escritura es la posibilidad que hace que la realidad pueda ser real... La literatura -y la literatura está aquí por todas las otras artes- dice la realidad. Por ello, la literatura es cuestión de realidad, de verdad, de moral, y... de muerte (Marchant, 2012: $245)^{6}$.

Es la literatura, cuando renuncia a la fijación de una verdad generalizable, la que para Marchant tiene potencialidades de crear una escena.

La obra literaria se muestra como espacio privilegiado para poder representar y significar este tipo de escena, que no podría ser relatada de manera directa ni naturalizada. La mediación del texto literario con sus posibilidades estratégicas de complejizar las múltiples intervenciones presentes en el vínculo del sujeto con el lenguaje, con la razón, consigo mismo y con su alrededor son centrales en la construcción del texto. Este está urdido en torno a la escena psicoanalítica que solo encuentra su forma de expresarse dentro del marco posibilitado por la literatura. En este sentido, me parece que el dispositivo se vuelve fructífero para leer Los siete locos y Los lanzallamas, pues permite evidenciar una relación problemática con una cultura y tradición literaria, haciendo articulables realidades sentidas como indecibles.

\section{A MODO DE CONCLUSIÓN}

Si volvemos a considerar los planteamientos iniciales, este texto parte de la convicción de que la emergencia de las teorías psicoanalíticas significó una verdadera revolución en las miradas sobre el sujeto, su relación consigo mismo, con los otros, con el lenguaje, la sexualidad y el deseo. En este sentido, se entiende el psicoanálisis en tanto artefacto cultural complejo, que permea múltiples prácticas discursivas y comprensiones del sujeto, mucho más allá de los círculos de especialistas, médicos, psiquiatras, psicólogos, psicoanalistas y sus pacientes, formando parte de lo que ha sido llamado el mundo de lo "psi”. Las escenas psicoanalíticas en la obra de Roberto Arlt se inscriben dentro de este contexto de las transformaciones de concepciones del sujeto movilizadas por la

\footnotetext{
${ }^{6}$ Los puntos suspendidos pertenecen al original.
} 
irrupción del psicoanálisis. El sujeto que podemos rastrear en las obras Los siete locos y Los lanzallamas, es un sujeto psicoanalítico, en el sentido trazado: un sujeto que no puede ser pensado sin las categorías elaboradas por las teorías psicoanalíticas. Un sujeto que padece de fuerzas que se escapan a explicaciones racionales, es preso de deseos que no puede entender ni expresar, mantiene relaciones (auto)destructivas, está atrapado en historias pasadas que se manifiestan sintomáticamente en el presente. Un sujeto que se conforma desde el deseo, el trauma, la represión: un sujeto sin lugar a dudas atravesado y trizado por el inconsciente. El sujeto ya no aparece configurado a partir de la supremacía y confianza en la racionalidad moderna, en tanto garante de bienestar y progreso, sino como cúmulo de fuerzas y pulsiones contradictorias e incontrolables. Es un sujeto movido por su inconsciente, por deseos que no comprende ni puede expresar, por recuerdos traumáticos reprimidos y pulsiones autodestructivas.

A partir de la circulación múltiple de las teorías psicoanalíticas, muchas prácticas discursivas se ven afectadas por estas concepciones transformadas del sujeto, incluyendo el espacio literario. La literatura se comprenderá como un lugar privilegiado para representar y significar esta relación problemática con la razón moderna, complejizando el vínculo del sujeto con el lenguaje, consigo mismo y con los otros. A partir de escenas psicoanalíticas, marcadas por la presencia de una situación de confesión desde la cual aparece una verdad oculta, que solo se logra articular en un dialogismo entre dos figuras -analizado y analista-, la obra literaria se abre a la representación de este sujeto complejo.

Las escenas de confesión en Roberto Arlt se convierten de este modo, desde su particularidad, en una cifra de un campo -el literario- que se ve removido por transformaciones de importante impacto. Los sujetos que deambulan por las obras de Arlt aparecen en tanto efectos de múltiples contradicciones y tensiones, siendo el lenguaje un medio equívoco y siempre engañoso para dar cuenta de sí. Las verdades que se vislumbran en las conversaciones son inestables y son sometidas, una y otra vez, a nuevas disquisiciones. Las escenas de confesión, que han servido de marco para guiar la lectura propuesta, darían cuenta de un mundo amenazado, donde las seguridades que antaño solían guiar una vida -basadas en nociones, tales como una verdad a instaurar, una salud a preservar, una autenticidad a alcanzar, una normalidad que establecer y un bienestar que perseguir- se ven vulneradas. Dicho en palabras de Oscar Masotta:

La obra de Arlt, entonces, es el estertor de una época donde lo que se sabe de la vida se mezcla con la vida, donde el conocimiento no se separa de la existencia, donde la confusión y el equívoco comienzan a tener un valor de verdad (Masotta, 2008: 29).

Lo que Masotta en su pionero estudio sobre Arlt dictamina acerca de su obra puede ser puesto en relación con lo que podríamos llamar la época psicoanalítica. Los siete locos y Los lanzallamas dan cuenta de la importancia de las teorías psicoanalíticas para toda la cultura del siglo XX, que es "en muchos sentidos el siglo del Psicoanálisis" (Plotkin en Ruperthuz, 2015: 20).

BIBLIOGRAFÍA

ARLT, Roberto (2007). Los siete locos. Gualeguaychú: Tolemia. 
ARLT, Roberto (2008). Los lanzallamas. Gualeguaychú: Tolemia.

CHÁVEZ JimÉNEZ, Daniar. "El equilibrio del diálogo: Los siete locos y Los lanzallamas de Roberto Arlt”. Latinoamérica. Revista de estudios latinoamericanos 50 (2010).

FREUD, Sigmund (2012). El porvenir de una ilusión, el malestar en la cultura, y otras obras (1927-1931). Buenos Aires / Madrid: Amorrortu Editores.

LUDMER, Josefina (2011). El cuerpo del delito: un manual. Buenos Aires: Eterna Cadencia Editora.

Marchant, Patricio (2012). Sobre árboles y madres. Buenos Aires: La Cebra.

MasotTA, Oscar (2008). Sexo y traición en Roberto Arlt. Buenos Aires: Eterna Cadencia Editora.

PIGLIA, Ricardo (2001). Crítica y ficción. Barcelona: Anagrama.

PLOTKIN, Mariano Ben (2003). Freuden las pampas. Buenos Aires: Editorial Sudamericana.

ROWNER, Ilai (2015). The Event, Literature and Theory. Lincoln/London: University of Nebraska Press.

RuPERTHUZ, Mariano (2015). Freudy los chilenos. Un viaje transnacional (1910-1949). Santiago de Chile: Pólvora Editorial.

SAÍTTA, Sylvia. "Roberto Arlt: la conspiración de la literatura”. Revista Ñ (2005)

SÁNCHEZ, Cecilia (2005). Escenas del cuerpo escindido: ensayos cruzados de filosofía, literatura y arte. Santiago de Chile: Editorial Cuarto propio.

VEzzETTI, Hugo (1996). Freud en Buenos Aires. Buenos Aires: Universidad Nacional de Quilmes.

Williams, Linda Ruth (1995). Critical Desire. Psycoanaylisis and the Literary Subject. London: Edward Arnold.

ŽıžEK, Slavoj (2016). Acontecimiento. Madrid: Sexto Piso. 